\title{
Medtronic Mosaic porcine bioprosthesis: Assessment of 12-year performance
}

\author{
W. R. Eric Jamieson, MD, ${ }^{\mathrm{a}}$ Friedrich-Christian Riess, MD, ${ }^{\mathrm{b}}$ Peter J. Raudkivi, MD, ${ }^{\mathrm{c}}$ Jacques Metras, MD, ${ }^{\mathrm{d}}$ \\ Edward F. G. Busse, MD, ${ }^{\mathrm{e}}$ Jacob Goldstein, MD, ${ }^{\mathrm{f}}$ and Guy J. Fradet, MD ${ }^{\mathrm{a}}$
}

Background: The Mosaic porcine bioprosthesis (Medtronic, Inc, Minneapolis, Minn) was approved in 2000 by the US Food and Drug Administration. Clinical performance was evaluated in 6 centers.

\begin{abstract}
Methods: From 1994 to 2000, 797 patients (mean age 69 years) had aortic valve replacement (AVR) and 232 (mean 67 years) had mitral valve replacement (MVR). Concomitant coronary artery bypass grafting was performed with aortic valve replacement $(45.4 \%)$ and mitral valve replacement $(43.5 \%)$. Mean follow-ups were 7.5 years for aortic position and 7.3 years for mitral position.
\end{abstract}

Results: Early mortalities were $2.8 \%$ for AVR and 3.0\% for MVR. Late mortalities were $4.2 \%$ /patient-year for AVR and 5.1\%/patient-year for MVR. Overall 12-year survivals were 55.8\% $\pm 3.7 \%$ for AVR and $43.9 \% \pm$ $7.4 \%$ for MVR. Twelve-year freedoms from valve-related mortality were $87.1 \% \pm 3.1 \%$ for AVR and $82.5 \% \pm$ $7.7 \%$ for MVR. Twelve-year freedoms from reoperation were $84.0 \% \pm 3.3 \%$ for AVR and $82.5 \% \pm 7.5 \%$ for MVR. Freedoms from structural valve deterioration (SVD) by explant reoperation at 12 years for AVR were $93.3 \% \pm 2.6 \%$ for patients at least 60 years old and $75.9 \% \pm 9.3 \%$ for patients younger than 60 years. Freedoms from SVD by explant reoperation at 10 years for MVR were $95.3 \% \pm 7.8 \%$ for patients at least 70 years old and $84.0 \% \pm 9.3 \%$ for patients younger than 70 years. Hemodynamic performance data at 1 year for AVR (sizes $21-27 \mathrm{~mm}$ ) were mean systolic gradient range $13.7 \pm 4.8$ to $10.3 \pm 3.2 \mathrm{~mm} \mathrm{Hg}$ and effective orifice area range $1.5 \pm 0.3$ to $2.5 \pm 0.4 \mathrm{~cm}^{2}$. For MVR (sizes $25-31 \mathrm{~mm}$ ), data were mean diastolic gradient range $6.7 \pm 1.7$ to $3.7 \pm 0.9 \mathrm{~mm} \mathrm{Hg}$ and effective orifice area range $1.9 \pm 0.3$ to $2.4 \pm 0.6 \mathrm{~cm}^{2}$.

Conclusions: Overall performance of Mosaic porcine bioprosthesis to 12 years is satisfactory. Freedoms from SVD by explant reoperation were most satisfactory for aortic position in patients at least 60 years old and mitral position in patients at least 70 years old. Overall actuarial freedom from SVD by explant reoperation is encouraging for patients with MVR. (J Thorac Cardiovasc Surg 2011;142:302-307)

Supplemental material is available online.

The Medtronic Mosaic porcine bioprosthesis (Medtronic, Inc, Minneapolis, Minn), a third-generation prosthesis, was introduced in 1994 as an investigational prosthesis under the US Food and Drug Administration (FDA) investigational device exemption evaluation. The prosthesis

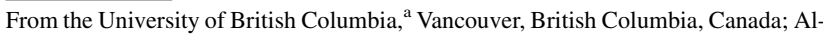
bertinen Krankenhaus, ${ }^{\mathrm{b}}$ Hamburg, Germany; Auckland City Hospital, ${ }^{\mathrm{c}}$ Auckland, New Zealand; Hôpital Laval, ${ }^{\text {d }}$ Quebec, Quebec, Canada; Regina General Hospital, ${ }^{\text {e }}$ Regina, Saskatchewan, Canada; and Monash Medical Center, ${ }^{\mathrm{f}}$ Clayton, Victoria, Australia.

Disclosures: This study was supported by Medtronic, Inc, Minneapolis, Minn.

Presented to the Society for Heart Valve Disease, Berlin, Germany, June 27-30, 2009.

Mosaic porcine bioprosthesis is manufactured by Medtronic, Inc, Minneapolis, Minn.

Received for publication July 11, 2010; accepted for publication Aug 23, 2010; available ahead of print Jan 31, 2011.

Address for reprints: W. R. Eric Jamieson, MD, Vancouver General Hospital, No. 3500-2700 Jim Pattison Pavilion, 855 W 12th Ave, Vancouver, BC V5Z 1M9, Canada (E-mail: eric.jamieson@vch.ca).

0022-5223/\$36.00

Copyright (c) 2011 by The American Association for Thoracic Surgery doi:10.1016/j.jtcvs.2010.08.090
}

introduced advanced technology to address altered durability of earlier bioprostheses. The Medtronic Mosaic has the tissue fixed with glutaraldehyde while in a physiologic state, incorporating predilatation of the aortic root, and treated with the long-chain fatty acid $\alpha$-amino oleic acid to bind to the residual aldehyde moieties to mitigate calcification.

The regulatory study commenced in 1994, with 17 primary centers participating in a prospective, nonrandomized, multicenter trial in February 1994 in Europe and September 1994 in Canada. The Medtronic Mosaic porcine bioprosthesis was approved by the US FDA in 2000, which was followed by a regulatory longitudinal study in the 6 participating centers that was closed July 14, 2002. The evaluation of the prosthesis continued in the 6 original participating centers, with a post-FDA longitudinal study sponsor-initiated evaluation commencing August 19, 2004.

The reporting on the Medtronic Mosaic porcine bioprosthesis has dealt with early to midterm clinical performance, particularly related to thromboembolism and hemodynamic performance. ${ }^{1-3}$ The purpose of this report is to document the longitudinal experience of the 6 participating centers with regard to reoperation for valve-related complications, 


\section{Abbreviations and Acronyms \\ $\mathrm{AVR}=$ aortic valve replacement \\ FDA $=$ Food and Drug Administration \\ $\mathrm{MVR}=$ mitral valve replacement \\ SVD $=$ structural valve deterioration}

as well as hemodynamic performance data from 1 participating center designated to perform this component of the study.

\section{MATERIALS AND METHODS}

The total study population incorporated 1029 patients who received Medtronic Mosaic porcine bioprostheses between 1994 and 2000. Institutional ethical approval was achieved at each center, and informed consent was obtained from the respective patients. The longitudinal evaluation was conducted in 2 phases: the regulatory study which closed in July 2002, and the industry-sponsored study that commenced August 2004. The initial regulatory study, with 6 centers participating, incorporated aortic valve replacement (AVR) in 797 patients (mean age 69 years, range 21-88 years) and mitral valve replacement (MVR) in 232 patients (mean age 67 years, range $17-84$ years). In the AVR population, 710 patients were at least 60 years old and 87 were younger than 60 years, whereas in the MVR population, 126 were at least 70 years old and 106 were younger than 70 years. Concomitant coronary artery bypass grafting was performed in $45.4 \%$ of AVR recipients and $43.5 \%$ of MVR recipients.

At the completion of the regulatory longitudinal study in July 2002, there were 702 AVR recipients and 202 MVR recipients alive. These patients were asked for new consent for the industry-sponsored phase, with 612 AVR recipients and 160 MVR recipients consenting.

Prospective echocardiographic evaluation was conducted in the participating center in Europe as part of the overall study protocol. This is reported in the Results section.

\section{Follow-up}

The cumulative follow-ups were 6010.1 years for AVR and 1683.1 years for MVR. The mean follow-up for AVR was $7.5 \pm 3.9$ years (median 8.2 years), and that for MVR was $7.3 \pm 3.9$ years (median 8.7 years). The follow-up in each center was conducted by institutional procedures to evaluate reoperation for valve-related complications such as structural valve deterioration (SVD). Serial echocardiograms were obtained at the Hamburg, Germany center. Follow-up was complete for $90.3 \%$ of AVR recipients and $92.7 \%$ of MVR recipients. Study design requirement called for regranting of consent at the end of the regulatory study phase. The closing interval of follow-up was January 7, 2009. Of the 797 patients who underwent AVR, 143 patients $(17.9 \%)$ were not available for the industrysponsored study: 66 patients refused to continue in the study, 43 patients could not be located, 10 patients moved to a different geographic area, and 24 patients had other reasons for being unavailable for follow-up. The percentage of patients unavailable for follow-up, excluding patients who refused to continue in the study, was $9.7 \%$. Of the 232 patients who underwent MVR, 31 patients (13.4\%) were unavailable for the industrysponsored study: 14 patients refused to continue in the study, 8 patients could not be located, 3 patients moved to a different geographic area, and 6 patients had other reasons for being unavailable for follow-up. The percentage of patients unavailable for follow-up, excluding patients who refused to continue in the study, was $7.3 \%$.

The unavailability for follow-up rates of $9.7 \%$ for AVR and $7.3 \%$ for MVR were contributed to by patients who dropped out of follow-up be- tween the 2 phases of the study. The major limitation of the study was this lack of follow-up years between the 2 phases of the study; during the interval, however, all 6 centers documented reoperations for SVD, and these were included in the analysis. During the interval, there were 9 AVR SVD reoperations recorded but no MVR SVD reoperations.

\section{Statistical Analysis}

Patient survival was determined according to valve position by KaplanMeier methodology. The definitions of valve-related complicationsthrombosis, SVD, nonstructural dysfunction (inclusive of periprosthetic leak), periprosthetic leak, and valve-related reoperation-form part of the documents on "Guidelines for Reporting Morbidity and Mortality after Cardiac Valvular Operations (Interventions)." ${ }^{4,5}$ The early mortality data ( $\leq 30$ days) were reported as crude rates. The overall mortality data were reported as linearized rates for the overall times, incorporating early and late intervals.

The freedom from SVD demonstrated by reoperation, valve-related reoperation, and valve-related mortality were determined by both actuarial and actual or cumulative incidence methodologies. The analyses of age groups (AVR $\leq 60$ and $>60$ years and MVR $\leq 70$ and $>70$ years) were conducted on the basis of considered indications for bioprostheses. The freedoms from SVD by reoperation were also analyzed by age groups 65 years and older and younger than 65 years for both AVR and MVR in accordance with the recommendations for prosthesis type by the American College of Cardiology and American Heart Association guidelines. ${ }^{6}$

\section{RESULTS}

The early mortalities were $2.8 \%$ for AVR and $3.0 \%$ for MVR. The overall mortalities were $4.2 \%$ /patient-year for AVR and 5.1\%/patient-year for MVR. The overall survivals for the AVR population were $55.8 \% \pm 3.7 \%$ at 12 years and $62.5 \% \pm 2.3 \%$ at 10 years; those for MVR were $43.9 \% \pm$ $7.4 \%$ at 12 years and $58.6 \% \pm 4.5 \%$ at 10 years $(P=.12)$. The survivals for patients undergoing AVR at 60 years and older and at younger than 60 years are illustrated in Figure 1 $(P=.002)$. The survivals for patients undergoing MVR at 70 years and older and at younger than 70 years are illustrated in Figure $2(P=.11)$. The actuarial freedoms from valve-related mortality at 12 years were $87.1 \% \pm 3.1 \%$ for AVR and $82.5 \% \pm 7.7 \%$ for MVR $(P=.77)$.

The etiologic reasons for AVR and MVR reoperations are detailed in Table 1. Thrombosis was the cause of 4 AVR and 2 MVR reoperations. There were 28 AVR reoperations for SVD and 9 MVR reoperations for SVD.

Figures 3 through 6 illustrate the complete actuarial analysis of SVD by explant reoperation, and Figures E1 and E2 illustrate actual (cumulative incidence) data. The freedoms from SVD reoperation by actuarial analysis at 12 years were $91.0 \% \pm 2.7 \%$ for AVR and $91.8 \% \pm$ $5.9 \%$ for MVR $(P=.53$; Figure 3$)$. The freedoms from SVD reoperation by American College of Cardiology and American Heart Association guidelines for age categories 65 years and older and younger than 65 years are summarized in Table 2.

The actuarial freedoms for AVR reoperation for SVD by age groups 60 years and older and younger than 60 years are illustrated in Figure 4. The freedoms at 12 years were 
SURVIVAL AVR $>=60 \&<60$ at $12 \mathrm{yrs}$

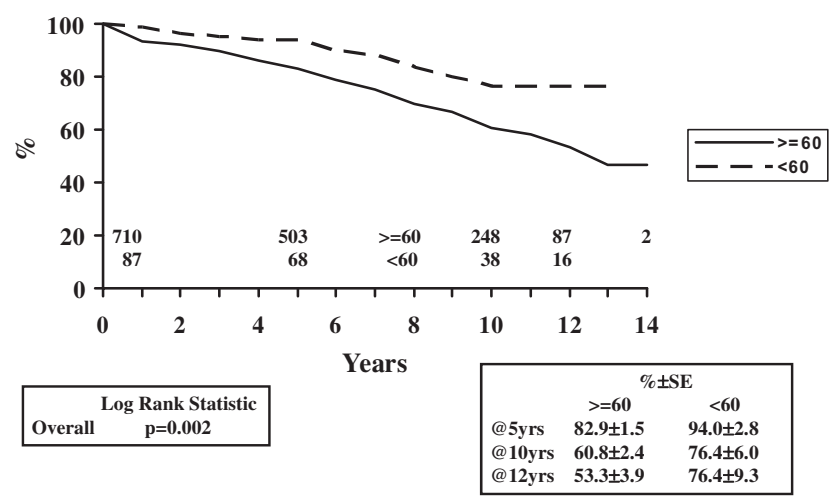

FIGURE 1. Survival for patients undergoing aortic valve replacement at 60 years and older and younger than 60 years.

$93.3 \% \pm 2.6 \%$ for 60 years and older and $75.9 \% \pm 9.3 \%$ for younger than 60 years $(P<.0001)$. The actuarial freedoms for MVR reoperation for SVD by age groups 70 years and older and younger than 70 years are shown in Figure 5. The freedoms at 10 years were $95.3 \% \pm 3.4 \%$ for 70 years and older and $94.5 \% \pm 3.9 \%$ for younger than 70 years $(P=.47)$.

The actual (cumulative incidence) freedoms from AVR and MVR reoperations for SVD stratified by age groups are presented in Figures E1 and E2. The freedoms from AVR reoperation for SVD at 12 years were $95.9 \% \pm$ $1.1 \%$ for 60 years and older and $80.6 \% \pm 5.0 \%$ for younger than 60 years. The freedoms from MVR reoperation for SVD at 12 years were $96.7 \% \pm 1.9 \%$ for 70 years and older and $90.3 \% \pm 4.4 \%$ for younger than 70 years. The Weibull analysis for SVD in AVR and

\section{SURVIVAL MVR $>=70 \&<70$ at $10 \mathrm{yrs}$}

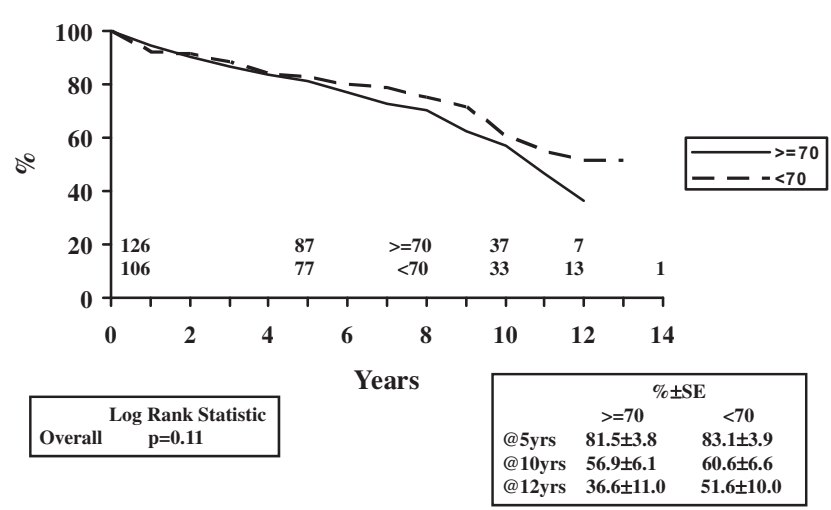

FIGURE 2. Survival for patients undergoing mitral valve replacement at 70 years and older and younger than 70 years.
TABLE 1. Reoperation etiologies

\begin{tabular}{lcc}
\hline \multicolumn{1}{c}{ Reason } & $\begin{array}{c}\text { Aortic valve } \\
\text { replacement }\end{array}$ & $\begin{array}{c}\text { Mitral valve } \\
\text { replacement }\end{array}$ \\
\hline Thrombosis & 4 & 2 \\
Endocarditis & 20 & 3 \\
Paravalvular leak & 8 & 4 \\
Nonstructural dysfunction & 4 & - \\
Structural valve deterioration & 28 & 9 \\
Incidental replacement & 3 & - \\
Total & 67 & 18 \\
\hline
\end{tabular}

MVR groups (Figure 6) demonstrates similar performances for AVR and MVR with regard to SVD.

The analysis of the cases of SVD consisted of echocardiographic, operative, pathologic, and radiologic findings. For the 28 SVD cases in the AVR group, the average age at implantation was 59.0 years and average duration since implantation was 9.3 postoperative years. Leaflet tear was the predominant lesion, with or without calcification. Perforation was identified in 4 cases of AVR. Stent dehiscence was identified in 1 case of AVR. Pannus (1-3 mm of tissue overgrowth) was incidentally observed in 14 cases of AVR. Reported or healed endocarditis was considered in 2 AVR cases, but the final diagnosis in both was SVD.

The average age of the 9 MVR recipients with SVD was 59.2 years, and the average duration since implantation was 9.1 postoperative years. For the 9 cases of SVD in the MVR group, leaflet tear was predominant, with or without calcification lesions. Perforation was identified in 1 case of MVR. Pannus was also observed in 4 cases of MVR.

Radiographs were evaluated in 13 cases (11 AVR and 2 MVR). Commissural calcification was a significant finding in 12 cases overall, at 1 to 3 commissures with

\section{FREEDOM FROM VALVE-RELATED (SVD) REOPERATION (Actuarial) AVR \& MVR}

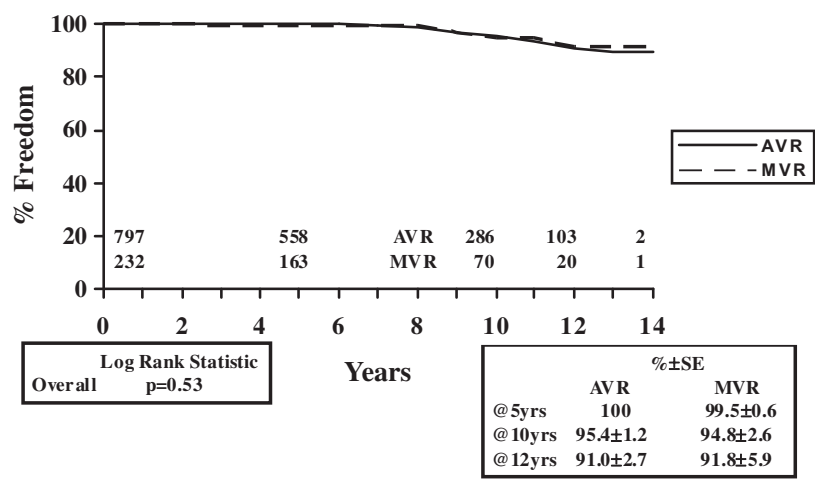

FIGURE 3. Actuarial freedoms from reoperation for structural valve deterioration for aortic valve replacement $(A V R)$ and mitral valve replacement $(M V R)$. 
FREEDOM FROM VALVE-RELATED (SVD)

REOPERATION (Actuarial) AVR $>=60 \&<60 \mathrm{yrs}$

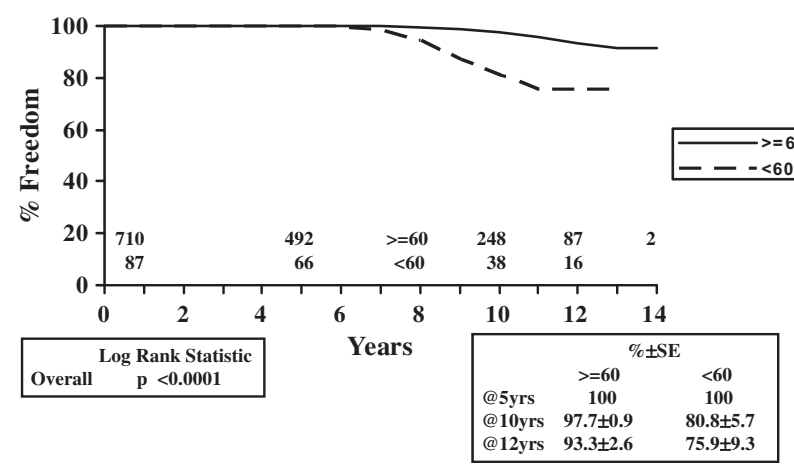

FIGURE 4. Actuarial freedoms from reoperation for structural valve deterioration for aortic valve replacement at 60 years and older and younger than 60 years.

accompanying leaflet calcification. The 2 MVR recipients with commissural calcification identified also had evidence of leaflet calcification on the radiologic evaluation.

Hemodynamic evaluations of AVR and MVR are graphically illustrated in Figures E3 and E4. The aortic mean systolic gradient for all valve sizes ranged from $12.5 \pm$ $5.1 \mathrm{~mm} \mathrm{Hg}$ at 1 year to $15.8 \pm 8.3 \mathrm{~mm} \mathrm{Hg}$ at 10 years. The effective aortic area ranged from $1.9 \pm 0.5 \mathrm{~cm}^{2}$ at 1 year to $1.7 \pm 0.4 \mathrm{~cm}^{2}$ at 10 years. The mitral mean diastolic gradient for all valve sizes ranged from $4.9 \pm$ $1.6 \mathrm{mg} \mathrm{Hg}$ at 1 year to $3.6 \pm 0.6 \mathrm{~mm} \mathrm{Hg}$ at 10 years. The effective mitral area ranged $2.0 \pm 0.5 \mathrm{~cm}^{2}$ at 1 year to 2.9 $\pm 0.7 \mathrm{~cm}^{2}$ at 10 years.

\section{DISCUSSION}

The Medtronic Mosaic porcine bioprosthesis, which was introduced in 1994 with advanced technology for tissue preservation and calcium mitigation, is approaching time for

FREEDOM FROM VALVE-RELATED (SVD)

REOPERATION (Actuarial) MVR $>=70 \&<70 y r s$

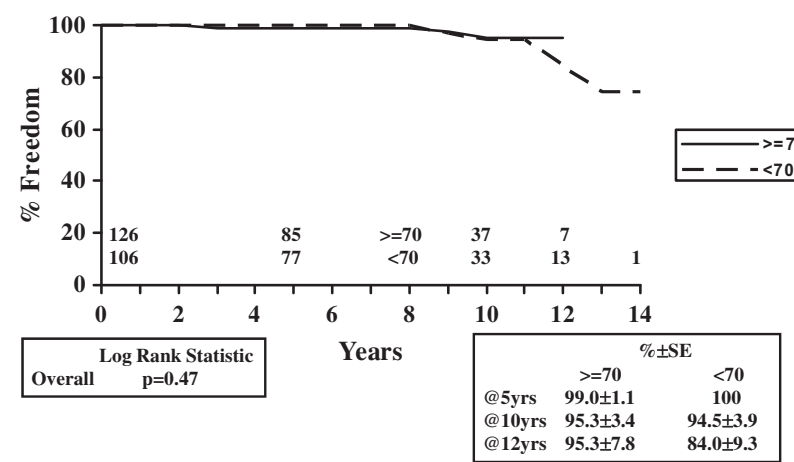

FIGURE 5. Actuarial freedoms from reoperation for structural valve deterioration for mitral valve replacement at 70 years and older and younger than 70 years. assessment of durability. There has been limited documentation addressing the durability of this bioprosthesis. The publications to date have evaluated thromboembolism and thrombosis, as well as hemodynamic performance. ${ }^{1-3,7-10}$

In 2002, Eichenger and colleagues ${ }^{7}$ reporting on 561 patients from 5 European centers reported 1 case of SVD in 451 AVRs at a mean follow-up of 3.2 years. The second report of SVD was by Botzenhardt and coauthors ${ }^{10}$ in 2004. That case, identified at 4 years, incorporated 2 calcified immobile leaflets.

The only report of the complete regulatory study population was published in 2004 by Fradet and colleagues. ${ }^{2}$ The 1029 patients had a mean follow-up of 4.3 years and a maximum of 8 years. There was $100 \%$ freedom of SVD for both aortic and mitral prostheses. The AVR recipients had a mean age of 70 years, and the MVR recipients had a mean age of 68 years.

In 2005, Jamieson and colleagues ${ }^{3}$ reported on the Vancouver population of 657 patients. This patient cohort incorporated 188 patients contributed to the regulatory trial. This report, at 6 years of evaluation, documented 4 cases of SVD ( 2 aortic and 2 mitral). There was also 3 cases of prostheses thrombosis ( 2 aortic and 1 mitral) requiring reoperation. The patients with SVD had 3 cases of leaflet tear with mild to moderate calcification and 1 case of severe calcific stenosis accompanying chronic renal failure and hemodialysis.

Riess and colleagues ${ }^{8}$ in 2007 reported on the single European center in the US FDA clinical trial. The mean follow-ups were 6.1 years for aortic prostheses and 5.4 years for mitral prostheses. The maximum follow-up for both was 10 years, and the mean age of both was 67 years. The report documented 4 cases of aortic SVD reoperation for regurgitation and stenosis. There were 4 cases of prosthesis thrombosis, 2 with congenital or acquired antithrombin III deficiency. There were no cases of mitral SVD.

Riess and colleagues ${ }^{9}$ again reported on the Medtronic Mosaic porcine bioprosthesis in 2009. They identified 9 cases of SVD among 255 AVR recipients and 1 case of SVD among 47 MVR recipients. The mean age for both positions was 67 years. The 9 AVR cases involved aortic regurgitation in 6 cases, 3 of these with combined aortic stenosis, and 3 cases with isolated aortic stenosis. The single MVR case involved stenosis. All of these patients came to explant reoperation for the SVD. This center was the single European center in our longitudinal study report. It was also the only center that conducted prospective echocardiography, but the report does not document SVD in nonoperative cases.

The only other report on the post-FDA study cohort of the 787 AVRs and 232 MVRs came in January 2007 in a marketing document produced by Medtronic. ${ }^{11}$ This document reported 17 AVR cases of SVD and 2 MVR cases of SVD at explant reoperation from the 6 post-FDA approval 
Weibull Analysis SVD

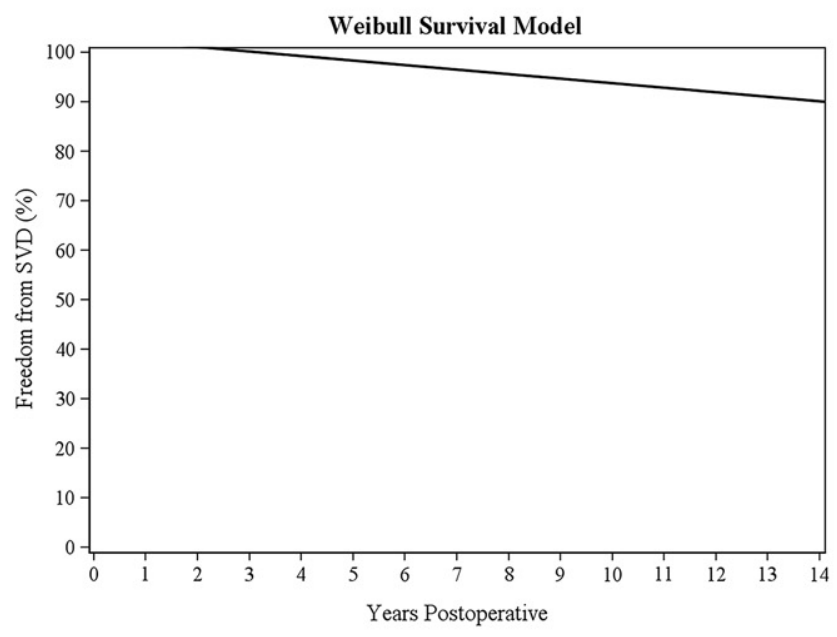

AVR - 28 Cases

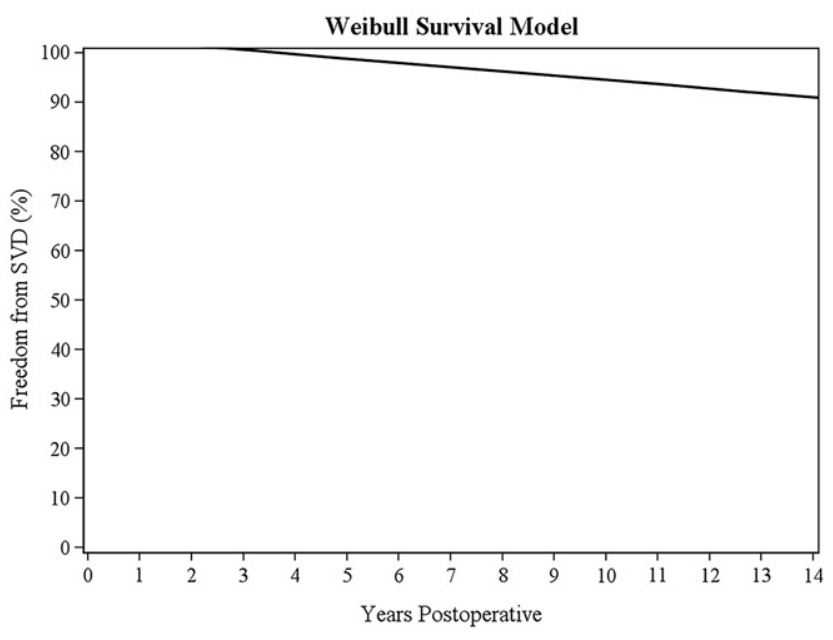

MVR - 9 Cases

FIGURE 6. Structural valve deterioration $(S V D)$ by Weibull analysis for aortic valve replacement $(A V R)$ and mitral valve replacement $(M V R)$.

centers. The freedoms from SVD by reoperation at 10 years for AVR were $97.8 \% \pm 3.9 \%$ for patients 65 years and older and $84.4 \% \pm 12.5 \%$ for patients younger than 65 years. The overall 10-year AVR freedom from SVD explant was $94.0 \% \pm 2.6 \%$; the overall 10 -year MVR freedom from SVD explant was $97.1 \% \pm 5.0 \%$.

The Vancouver experience of 1172 patients (705 AVR and 467 MVR) has again been documented (unpublished data). The mean age for both positions was 71 years. The mean follow-ups were 5.4 years for AVR and 4.5 years for MVR. The evaluation, completed in early 2007, revealed 7 cases of aortic SVD and 6 cases of mitral SVD at reoperation or autopsy. The actuarial freedoms from SVD at reoperation were $95.4 \%$ for AVR at 10 years and $97.6 \%$ for MVR at 8 years. There were an additional 14 AVR recipients and 2 MVR recipients with clinically diagnosed SVD, inclusive of echocardiographic examination. The predominant operative finding was leaflet tear. Pathologic and radiologic examinations revealed commissural calcification in a portion of the prostheses. There was also documented commissural dehiscence.

This study is the second documentation of the post-FDA study population. The mean follow-ups are now 7.5 years for AVR and 7.3 years for MVR. The number of SVD cases by explant reoperation has increased from 17 to 28 aortic prostheses and from 2 to 9 mitral prostheses. The freedom from SVD by reoperation is not differentiated by valve position. The predominant pathologic lesion has been leaflet tear, with leaflet calcification not being a predominant lesion. Commissural calcification at 1 to 3 commissural regions was also identified, but the study did not provide the opportunity to address the potential overall incidence of this finding in the general cohort population.
A limitation of the study is the lack of routine echocardiography in all centers, to correlate with radiographic evaluation of explanted prostheses to facilitate full evaluation of failure modes. Only the European center participated in prospective echocardiography as part of the study protocol. A further limitation of the study is the interval between the completion of the regulatory longitudinal study and the commencement of the sponsor-stimulated longitudinal study. This interval is reflected in the completeness of follow-up and the factors contributing to the extent of follow-up. The patients were subjected to a new consent process for the sponsor-stimulated longitudinal study, which resulted in reduction in the completeness of followup. Regardless of this limitation, cases of SVD that occurred in the interval were reported by each of the 6 participating centers and were included in the statistical analysis, probably lowering the freedom from SVD in the aortic position because of the lack of supporting follow-up during this interval.

TABLE 2. Actuarial freedom from reoperation for structural valve deterioration for aortic valve replacement and mitral valve replacement for patients 65 years old and older and patients younger than 65 years

\begin{tabular}{|c|c|c|c|}
\hline & \multicolumn{2}{|c|}{ Patients at risk } & \multirow{2}{*}{$\begin{array}{l}\text { Freedom at } 12 \\
(\%, \text { mean } \pm \mathrm{SD}\end{array}$} \\
\hline & $\mathbf{0 y}$ & $12 y$ & \\
\hline \multicolumn{4}{|c|}{ Aortic valve replacement } \\
\hline$\geq 65 \mathrm{y}$ & 632 & 69 & $95.9 \% \pm 2.3 \% *$ \\
\hline$<65 \mathrm{y}$ & 165 & 34 & $79.4 \% \pm 6.2 \%$ \\
\hline \multicolumn{4}{|c|}{ Mitral valve replacement } \\
\hline$\geq 65 \mathrm{y}$ & 179 & 13 & $95.1 \% \pm 2.9 \% \dagger$ \\
\hline$<65 \mathrm{y}$ & 53 & 7 & $94.3 \% \pm 5.2 \%$ \\
\hline
\end{tabular}


The study has revealed the most satisfactory freedoms from SVD diagnosed by explant reoperation for AVR in patients 60 years and older and for MVR in patients 70 years and older. The prosthesis rate of failure appears to be similar between aortic and mitral positions. The durability is particularly satisfactory for MVR. The Medtronic Mosaic porcine bioprosthesis needs continued evaluation and comparison with other bioprostheses that are approaching 20 years of follow-up.

\section{References}

1. Thomson DJ, Jamieson WR, Dumesnil JG, Burgess JJ, Peniston CM, Métras J, et al. Medtronic Mosaic porcine bioprosthesis: midterm investigational trial results. Ann Thorac Surg. 2001;71(5 Suppl):S269-72.

2. Fradet G, Bleese N, Busse E, Jamieson WR, Raudkivi P, Goldstein J, et al. The Mosaic valve clinical performance at seven years: results from a multicenter prospective clinical trial. J Heart Valve Dis. 2004;13:139-47.

3. Jamieson WR, Fradet GJ, MacNab JS, Burr LH, Stanford EA, Janusz MT, et al. Medtronic Mosaic porcine bioprosthesis: Investigational center experience to six years. J Heart Valve Dis. 2005;14:54-63.

4. Edmunds LH Jr, Clark RE, Cohn LH, Grunkemeier GL, Miller DC, Weisel RD. Guidelines for reporting morbidity and mortality after cardiac valvular operations. Ad Hoc Liaison Committee for Standardizing Definitions of Prosthetic Heart Valve Morbidity of the American Association for Thoracic Surgery and the Society of Thoracic Surgeons. J Thorac Cardiovasc Surg. 1996;112:708-11
5. Akins CW, Miller DC, Turina MI, Kouchoukos NT, Blackstone EH, Grunkemeier GL, et al. Guidelines for reporting mortality and morbidity after cardiac valve interventions. J. Thorac Cardiovasc Surg. 2008;135: 732-8.

6. Bonow RO, Carabello BA, Chattererjee K, et al, American College of Cardiology, American Heart Association Task Force on Practice Guidelines (Writing Committee to revise the 1998 guidelines for the management of patients with valvular heart disease), Society of Cardiovascular Anesthesiologists. ACC/AHA 2006 guidelines for the management of patients with valvular heart disease: a report of the American College of Cardiology/American Heart Association Task Force on Practice Guidelines (writing Committee to Revise the 1998 guidelines for the management of patients with valvular heart disease) developed in collaboration with the Society of Cardiovascular Anesthesiologists endorsed by the Society for Cardiovascular Angiography and Interventions and the Society of Thoracic Surgeons. J Am Coll Cardiol. 2006;48:1-48. Erratum in: J Am Coll Cardiol. 2007;49:1014.

7. Eichinger WB, Botzenhardt F, Gunzinger R, Kemkes BM, Sosnowski A Maiza D, et al. European experience with the Mosaic bioprosthesis. $J$ Thorac Cardiovasc Surg. 2002;124:333-9.

8. Riess FC, Bader R, Cramer E, Hansen L, Kleijnen B, Wahl G, et al. Hemodynamic performance of the Medtronic Mosaic bioprosthesis up to ten years. Ann Thorac Surg. 2007;83:1310-8.

9. Riess FC, Cramer E, Hansen L, Schiffelers S, Wahl G, Wallrath J, et al. Clinical results of the Medtronic Mosaic porcine bioprosthesis up to 13 years. Eur J Car diothorac Surg. 2009;37:145-53.

10. Botzenhardt F, Gansera B, Kemkes BM. Mid-term hemodynamic and clinical results of the stented porcine Medtronic Mosaic valve in aortic position. Thorac Cardiovasc Surg. 2004;52:34-41.

11. Medtronic Inc. Mosaic bioprosthesis: 10-year clinical update. Minneapolis Medtronic; 2007. p. 1-23. 
FREEDOM FROM VALVE-RELATED (SVD)

REOPERATION (Actual) AVR $>=60 \&<60 \mathrm{yrs}$

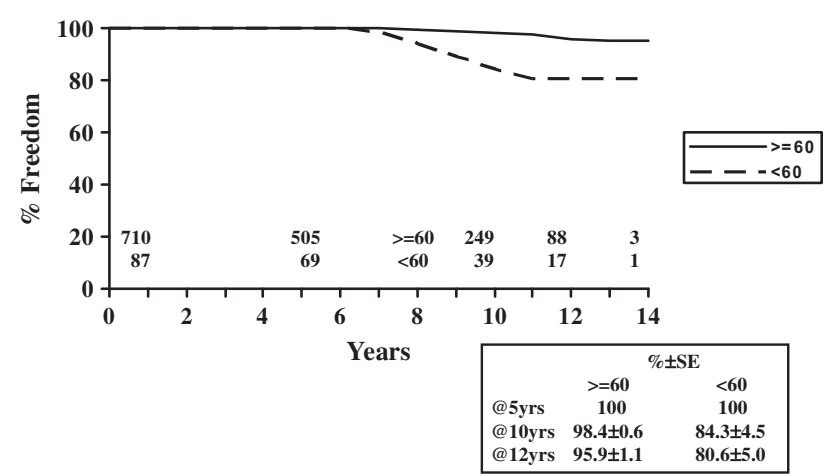

FIGURE E1. Actual freedoms (cumulative incidence) from reoperation for structural valve deterioration for aortic valve replacement at 60 years and older and younger than 60 years.

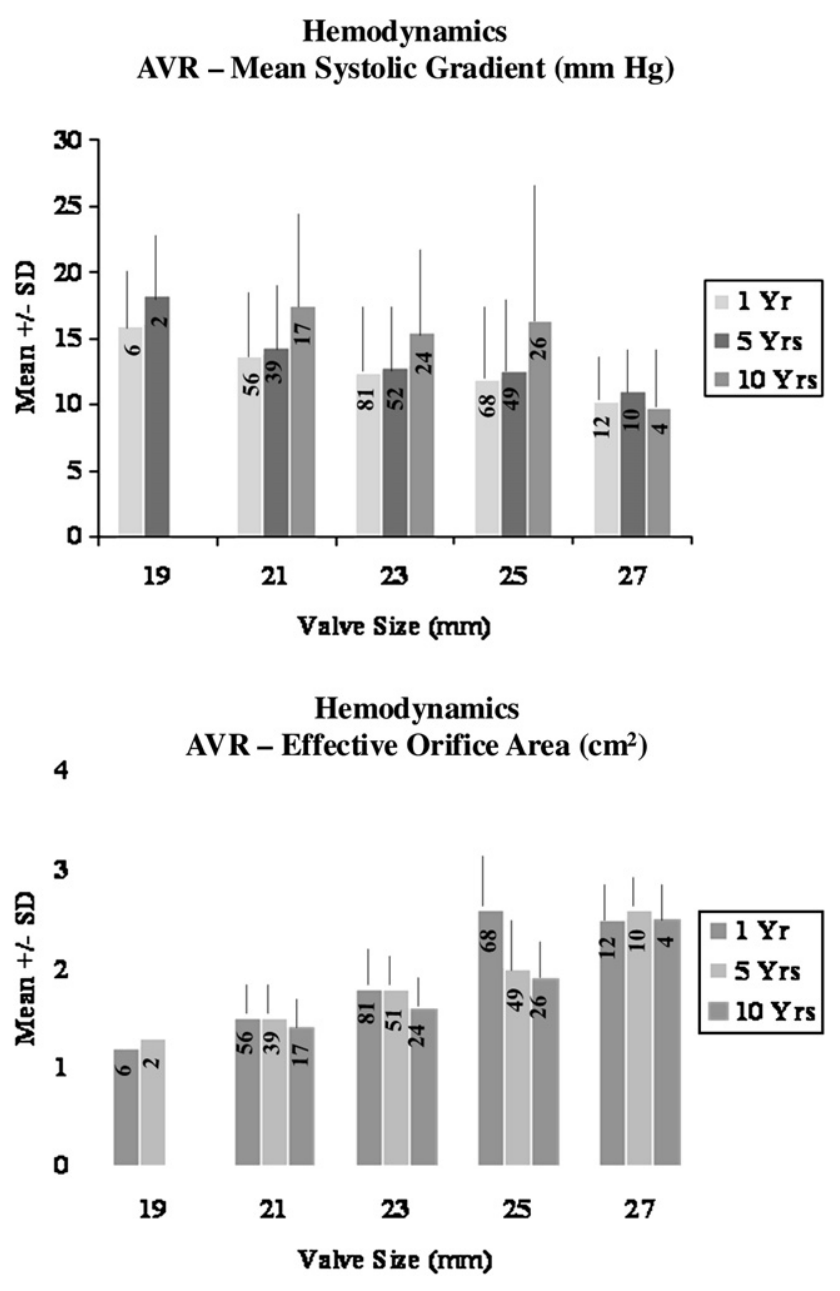

FIGURE E3. Hemodynamics for aortic valve replacement. A, Mean systolic gradient in millimeters of mercury. B, Effective orifice area in square centimeters.
FREEDOM FROM VALVE-RELATED (SVD)

REOPERATION (Actual) MVR $>=70 \&<70 \mathrm{yrs}$

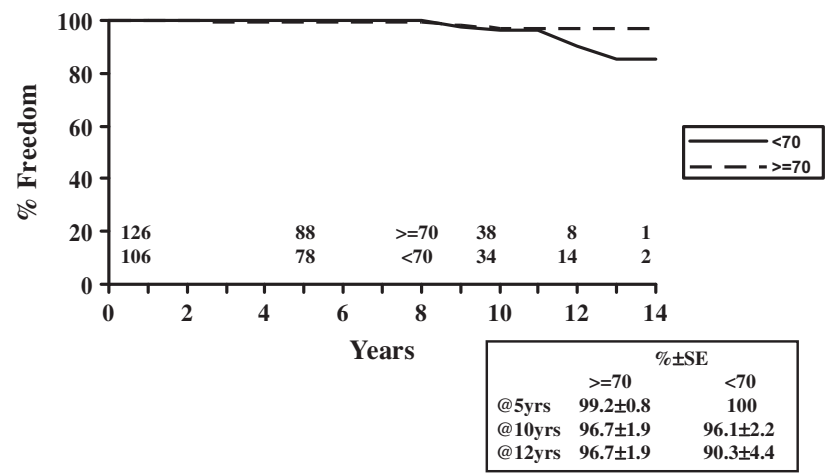

FIGURE E2. Actual freedom (cumulative incidence) from reoperation for structural valve deterioration for mitral valve replacement at 70 years and older and younger than 70 years. 


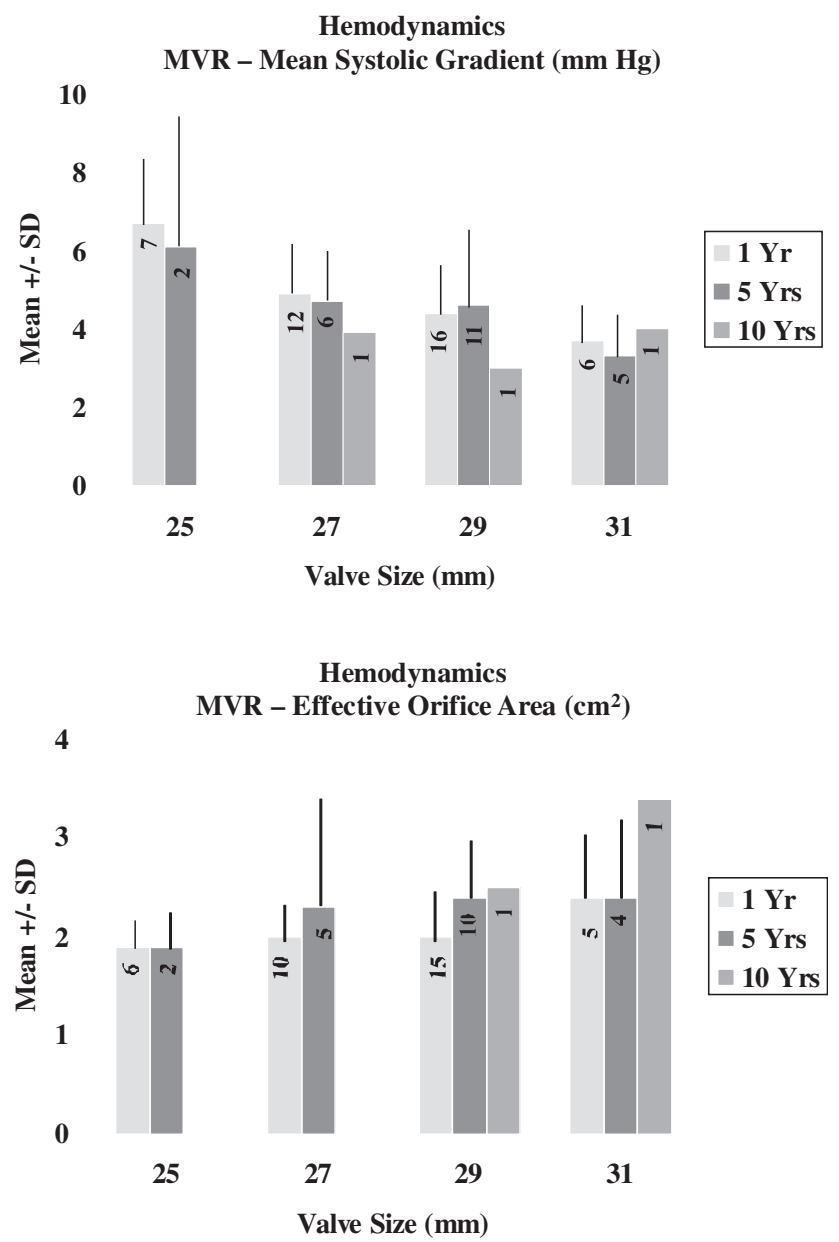

FIGURE E4. Hemodynamics for mitral valve replacement. A, Mean systolic gradient in millimeters of mercury. B, Effective orifice area in square centimeters. 